\title{
Robot Arm Structure Design Using Polyamide Evaluated by Finite Element Analysis
}

\author{
Somyot Kaitwanidvilai, ${ }^{1}$ Siwawong Buthgate, ${ }^{1 *}$ \\ Hisayuki Aoyama, ${ }^{2}$ and Poom Konghuayrob ${ }^{1}$ \\ ${ }^{1}$ Faculty of Engineering, King Mongkut's Institute of Technology Ladkrabang, \\ Chalongkrung Road, Ladkrabang, Bangkok 10520, Thailand \\ ${ }^{2}$ Department of Mechanical Engineering \& Intelligent Systems, University of Electro-Communications, \\ Chofugaoka, Chofu, Tokyo 182-8585, Japan
}

(Received April 21, 2019; accepted January 6, 2020)

Keywords: energy efficiency, finite element analysis, robot arm, cast iron, polyamide, aluminum

Robots have increasingly replaced humans for many jobs, including $24 \mathrm{~h}$ work, routine tasks, and dangerous jobs. However, the robot operating system has high power consumption in many processes. This has led to energy efficiency being the main focus. We have opted to build a robot with high strength, light weight, and low power consumption by reducing the weight of its components. Presently, we know that the structure of most robots in the world is made of metals, plastics, and composite materials. In this research, we designed the mechanical structure of robot arms with three different materials (cast iron, polyamide, and aluminum) using the finite element method to analyze and evaluate the possibilities of these materials. The dynamic load, power consumption, and mechanical characteristics were compared. It was found that polyamide could help lighten the weight by $40 \%$ and increase energy efficiency along with cost effectiveness by $41 \%$. Although polyamide is particularly easy to find, cast iron is stronger than polyamide.

\section{Introduction}

Currently, we are seeing many robots in factories, hospitals, department stores, and even our own homes. Robots have become part of human life because the current technology has progressed rapidly in all corners of the world. To produce more quality products and meet the needs of an everchanging market, the innovation and advances in robotic technology have helped to increase production efficiency. Some types of robot already use plastics as a component, resulting in the research and development of plastic robots. Plastics are an important material in components of robots including many industrial machines and are also used as a connecting or welding material in a robot assembly. Therefore, currently, plastics are drawing the interest of engineers and designers of robots, owing to their specific properties of light weight, durability, agility, adaptability, and tailorability of properties in accordance with

*Corresponding author: e-mail: Buthgate@gmail.com https://doi.org/10.18494/SAM.2020.2416 
the application. In Ref. 1, the casing cap of a parking brake cable was investigated by finite element analysis (FEA) and the results showed that the casing cap material can be changed from steel to the PA GF15 plastic. The results also showed that plastics can reduce the mass by around $21 \%$ and the cost of material by approximately $40 \%$. In Ref. 2 , the development of a new base for robot arms was investigated by FEA to analyze and evaluate the possibilities of all materials. The results showed that the base can be made of PA GF30 plastic to replace cast iron, thereby reducing the material cost by $15 \%$ and the weight by $80 \%$. In Ref. 3 , the reliability of the casing cap was examined and the results obtained by FEA simulation were compared with those obtained for a real sample using a testing machine. The FEA simulation and experimental results of the material revealed a 30\% reduction in cost and weight in both the design and production processes. In Ref. 4, a new design of a fixed-structure robust controller for the joint space control of a pneumatic robot arm was studied. The proposed technique was based on the concept of $H_{-}$loop shaping, which is a sensible method for robust controller design. However, on the basis of the simulation results, the conventional design with material properties was proposed to be retained as part of the new controller design. Experimental results verified the effectiveness of the proposed technique. In Ref. 5, a genetic algorithm was used to search for subcarriers suitable for subcarrier multiplexing (SCM) on a multimode fiber (MF). The suitable design showed that the material properties are useful in designing subcarriers at the peak of the passbands of the MF. The data of subcarriers are approximately threefold those obtained from the $3 \mathrm{~dB}$ intermodal bandwidth. In Ref. 6, a new technique of analyzing the resonance vibration problem, which is a major problem in a hard-disk-drive arm, by FEA was demonstrated. The results showed that the developed program can effectively simulate the resonance behavior determined from the computational results of accurately tailoring the material. In Ref. 7, the fiber Bragg gratings (FBGs) embedded in resin increased the Young's modulus of the resin material. FBGs embedded in various resin materials were examined as optical bend sensors. The obtained wavelengths were almost in agreement with theoretical values, increased linearly with the bending deflection, and were calculated using a composite beam model. In Ref. 8, the use of lightweight automotive parts made of thermoplastics was found to be an effective way of reducing $\mathrm{CO}$ emission. By using plastics, the bumper weight of plastic vehicles was reduced by $41 \%$ compared with that in the case of using steel. It was also found that the production cost of plastics was lower than that of steel. In Ref. 9, a composite polymer was studied to describe the mechanical properties of a nanocomposite polymer. The experimental results were analyzed to explain the limitations and description of the mechanical properties of polymers. In Ref. 10, the main purpose of the simulation was to analyze the stress rate of plastics, which depended on the polymer. The method used only mechanical tests and measured data to generate the real stress following the strain curve at different stress rates. In Ref. 11, a metal fuel tank of a public bus was replaced with a plastic fuel tank and its effect was evaluated by static and dynamic analyses as well as the FEA method. The purpose of this research was to show an analytical approach to preventing plastic tank damage. In Ref. 12, the purpose of the simulation was to analyze and study the feasibility of plastic application to modify the stress rate, which depended on the polymeric material. The results of stress and strain measurements resulted in approaches to reducing time, and relationships were fully implemented by FEA. In Ref. 13, taper roller 
bearings, an important part of gear reducers, affected both the meshing contact of the gears and the lubrication between the rollers and raceways of the bearings. The FEA technique for roller bearings was established by using the Reynolds equation and considering the surface roughness. Finally, the effects of the pretightening of the bearings were analyzed by considering the maximum stress and strain. In Ref. 14, the static analysis of linear elastic structures with uncertain responses to deterministic loads was addressed and an interval FEA method was based on an improved interval analysis was developed. The key idea of this novel method is the inclusion of an extra unitary interval in each uncertain parameter in order to keep physical properties linked to the finite elements in both the assembly and solution phases. In Ref. 15, the acoustic signals of transmission along a chain of spheres in biomedical applications of ultrasound and waveforms of relevance were investigated. The results showed the possible use of ultrasound in both therapeutic and diagnostic applications. The objective was achieved by generating signals with different harmonic contents. The results suggested that a comparison of experimental and FEA results for fluid loading was a suitable tool for performance investigation. In Ref. 16, the flexibility of links and joints for robot arms was considered. The results of the prestressed model analysis of the flexible robot arm using ANSYS Workbench software were compared. A reliable basis for the research methods of dynamic characteristics was provided. In Ref. 17, the buffer effect of a polyimide (PI) layer determined by a drop test was discussed and the structure of wafer level without underfill. The drop impact was calculated by FEA using a zooming technique. This research was focused on PI, which affects the shape factor. The results indicated a thick high-modulus PI. In Ref. 18, FEA was adopted to examine the connection of humanoid robot joints and other joints. Their failures and weaknesses were observed in the results of the analysis of the stress zone between the minimum and maximum stresses. The results of FEA revealed the potential sources of danger of the robot arm, and provided a theoretical basis for the optimization of the design of the humanoid robot structure. In Ref. 19, FEA was shown as the main method that allowed users to rapidly and accurately compute the stress and stress behavior of composite materials. This method was used to reduce the labor cost and determine the parameters. The calculation time was not more than $15 \mathrm{~h}$ and the stress error was not more than 4\%. Reference 20 showed the design of the resin guide vane in a borehole tapping system and used ANSYS software to analyze the stressstrain relationship with full loading. The results of the resin guide vane obtained by FEA showed that the maximum stress was less than the bending strength and the maximum displacement was markedly less than the displacement of minimum elongation. In Ref. 21, robotic origami was constructed from thin sheets of function material using rapid prototyping. The construction required a detailed study of 3D and 2D geometries, and 2D fabrication methods. This article reported advancement in the design and fabrication methodology of origami robots, with customizable functionality from the ground up. In Ref. 22, the underwater robots ROV and AUV were used for ocean explorations and underwater work, where the zoom body frame was examined by FEA. The carbon fiber reinforced polymer (CFRP) body frame dispersed applied external loads, FEA was carried out to test the CFRP, and samples with the material properties obtained from the test were used. In Ref. 23, the developed model was used in FEA to predict the macroscopic behavior of polycrystalline materials and the results showed 
that the model was effective in the simulation of the cyclic behavior of $\mathrm{Sn}-0.7 \mathrm{Cu}$ solder at different temperatures and strain rates. In Ref. 24, the FEA for the drop test was performed using both the stress-strain relationships at high and low strain rates. The test results of the stress-strain relationships at high strain rates were observed to be in agreement with those at low strain rates. In Ref. 25, the nonlinear friction was considered because it seriously affected the tracking accuracy of the robot. The tracking accuracy of the robot was significantly improved by effectively applying the desired signal. The results demonstrated the feasibility and effectiveness of the proposed control method. In Ref. 26, a robust solution to the trajectory tracking control problem under uncertainties and disturbances was obtained. Simulation and experimental results were explored to verify the effectiveness of the proposed control strategy. All reviewed research studies revealed that FEA is an efficient method for the analysis of material properties.

The highlight of our study, which is different from those of other studies, is the design structure of a robot arm made of polyamide, instead of cast iron, making it lighter and lower in cost. The plastic (polyamide), was investigated by FEA, the mechanical properties of the designed robot arm were studied, and the performance of cast iron, aluminum, and polyamide were compared

\section{Materials}

Material handling is the essence of robotics and, in the near future, some structural components of robots will be changed to reduce the weight. We already know that the structure of robots is made of metals, plastics, and composite materials. Metal is a common material of robots. It is among the most expensive robot materials in terms of both cost and weight. Steel and aluminum are common metals; although aluminum alloy is smoother and easier to use than steel, steel is markedly stronger. Plastic is a choice of material for manufacturers because it enables manufacturers to build shapes quickly to complete a model rapidly. It is also readily available and affordable, and plastic composites have a low weight-to-strength ratio. Some composites are both lightweight and very strong (i.e., carbon composites). However, strong composites are costly and less readily available. Construction materials should be chosen for their suitability for the job, functionality, or other requirements. The robot body is made using bars, rods, sheets, channels, and other forms. However, it must be sufficiently rigid enough to support the weight of motors, batteries, and other parts without undue bending or flexing.

\section{Methodology}

In this section, computer-aided engineering (CAE) software is used for analyzing and evaluating the possibilities of robotic materials. The key factors of the robotic design are strength, light weight, and low power consumption. The robot arm in this work is designed to have five degrees of freedom (DOFs), with four rotary joints and one prismatic joint. The number of DOFs is determined by the number of independent joint variables. 


\subsection{Robot arm design}

The robot arm system often consists of links, joints, actuators, controllers, and sensors, as shown in Fig. 1. There are two types of joint, namely, prismatic and rotary joints, for connecting neighboring links. In this work, the robot design is equipped with five servo motors to link the parts and induce arm movement, as shown in Fig. 2. Cast iron, polyamide, and aluminum are applied to the robot components. The weights and total weights of these materials are shown in Table 1. For a comparative study, the dynamics load, power consumption, and mechanical characteristic (max. stress) of the robot are used as criteria in choosing the simulation task.

The mechanical properties of cast iron, polyamide (PA66), and aluminum in the simulation models are presented in Table 2.
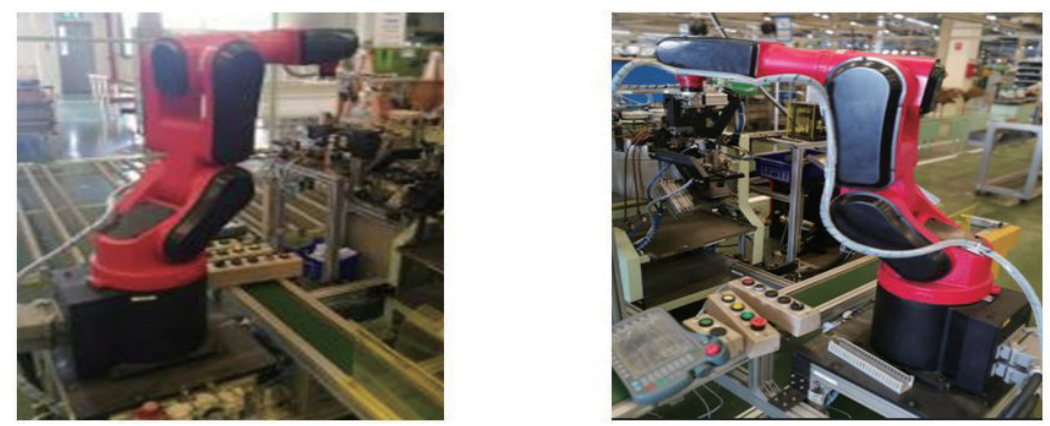

Fig. 1. (Color online) Robot arm in industry.

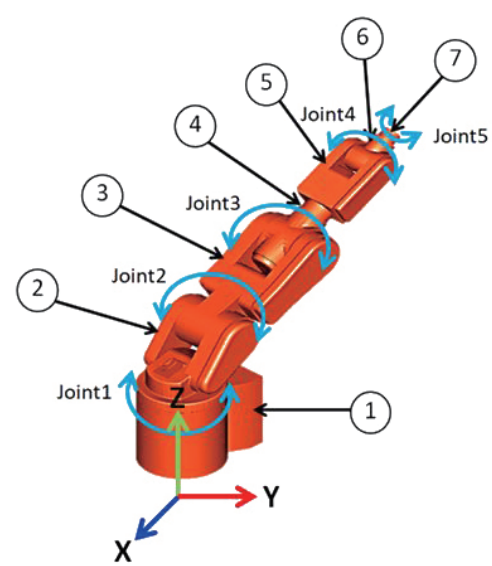

Fig. 2. (Color online) Robot arm components.
Table 1

Weights of cast iron, polyamide, and aluminum materials in each component and their total weights in the robot arm.

\begin{tabular}{|c|c|c|c|c|}
\hline \multirow{2}{*}{ No. } & \multirow{2}{*}{ Component } & \multicolumn{3}{|c|}{ Weight (kg) } \\
\hline & & Cast iron & Polyamide & Aluminum \\
\hline 1 & Base & 20.312 & 3.710 & 7.583 \\
\hline 2 & Link1 & 12.988 & 2.372 & 4.849 \\
\hline 3 & Link2 & 12.529 & 2.289 & 4.677 \\
\hline 4 & Link3 & 5.217 & 0.953 & 1.948 \\
\hline 5 & Link4 & 5.000 & 0.913 & 1.867 \\
\hline 6 & Link5 & 3.828 & 0.699 & 1.429 \\
\hline 7 & $\begin{array}{c}\text { Holder } \\
\text { (with load) }\end{array}$ & 0.630 & 0.630 & 0.630 \\
\hline Tota & & 60.504 & 11.566 & 22.983 \\
\hline
\end{tabular}

Table 2

Mechanical properties of cast iron, polyamide, and aluminum.

\begin{tabular}{lccc}
\hline \multirow{2}{*}{ Mechanical property } & \multicolumn{3}{c}{ Material } \\
\cline { 2 - 4 } & Cast iron & Polyamide & Aluminum \\
\hline Young's modulus $(\mathrm{GPa})$ & 180 & 6.3 & 72.4 \\
Density $\left(\mathrm{Kg} / \mathrm{mm}^{3}\right)$ & 7500 & 1370 & 2800 \\
Poisson's ratio & 0.294 & 0.340 & 0.33 \\
Yield strength $(\mathrm{MPa})$ & 200 & 216 & 414 \\
\hline
\end{tabular}




\subsection{Robot arm operation}

As a case study, the robot arm is used in the platform as part of a window regulator production facility. The robot arm has five servo motors, each motor for one DOF. All motors operate with 6 volts. There are five rotation DOFs in the arm and their rotation range is 180 degrees from the start to the end of the movement path (see Fig. 3). At the end of the movement path, the components are aligned straight at $45^{\circ}$ from the arm base and the path is for cover usage. The payload of the robot is a window regulator $(0.630 \mathrm{~kg})$ and the total distance of movement is $1900 \mathrm{~mm}$.

The multibody dynamics of moving parts are analyzed throughout the mechanical systems using MSC ADAM software. ADAM conditions for analyzing the dynamics characteristics are shown in Table 3.

\subsection{FEA}

Figure 4 shows the FEA simulation using the CATIA and CAE software programs with properties, mesh conditions, and all the material parameters used. Output showed dynamics load, stress, so forth.

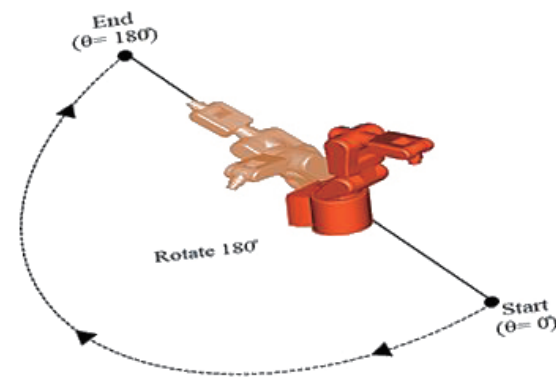

The joint rotation is determined by Joint $1=-90^{\circ} \times\left(1-\cos \left(360^{\circ} \times\right.\right.$ time $\left.)\right)$, Joint $2=-30^{\circ} \times\left(1-\cos \left(360^{\circ} \times\right.\right.$ time $\left.)\right)$, Joint $3=45^{\circ} \times\left(1-\cos \left(360^{\circ} \times\right.\right.$ time $\left.)\right)$, Joint $4=2^{\circ} \times\left(1-\cos \left(360^{\circ} \times\right.\right.$ time $\left.)\right)$, Joint $5=45^{\circ} \times\left(1-\cos \left(360^{\circ} \times\right.\right.$ time $\left.)\right)$.

Fig. 3. (Color online) Configuration of robot movement on platform of window regulator production facility.

Table 3

ADAM conditions.

\begin{tabular}{lccc}
\hline No. & Function & Parameters & Meaning \\
\hline 1 & Bodies & Modify body: mass & Input mass of product \\
2 & Bodies & Modify body: center of mass maker & Input the center of gravity (CG) of product \\
3 & Connectors & Joints: create rotary joint & Specify in 3 axes $(x, y, z)$ \\
4 & Motion & Joint motion: rotation & Selecting type of joint (rotary joint) \\
5 & Motion & Joint motion: function (time) & Selecting type of joint motion (rotation) \\
\end{tabular}

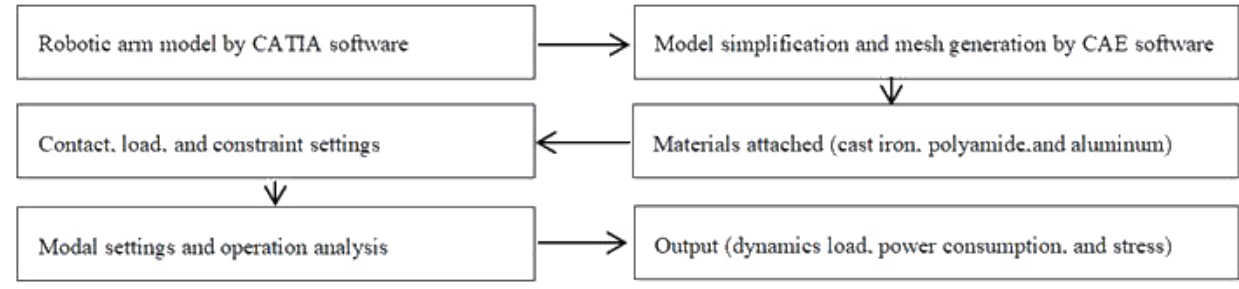

Fig. 4. FEA simulation using Catia and CAE software. 


\section{Results and Discussion}

The robot arm was mathematically modeled by the finite element method. The dynamics load, power consumption, and maximum stress were solved and implemented using the CAE software. Cast iron, polyamide, and aluminum were applied to robot components under the same driving trajectory.

\subsection{Multibody dynamics load}

The dynamic load and movement step of the robot arm are simulated in the $x, y$, and $z$ axes to determine the maximum force using ADAM software. The force and time during the simulation of the links on the three structures are presented in Fig. 5. The maximum magnitudes of resultant forces observed on the base component are 1276.14, 507.299, and $273.744 \mathrm{~N}$ for cast iron, aluminum, and polyamide, respectively. Because the total load is pressed down to the base, high forces and torques must be applied to drive the components. The weights and total loads of all materials are listed in Table 1.

Figure 6 shows the variation in joint torque with time during the simulation. Torque $(T)$ is defined as a turning or twisting force. It is important to determine the torque of each joint that drives the robot arm. The maximum torque $513107.20 \mathrm{~N} \cdot \mathrm{mm}$ is obtained for cast iron at joint 1 . This value is around 3 and 5.28 times higher than those of aluminum and polyamide because of its payload. The torque increases with increasing reach length and payload.

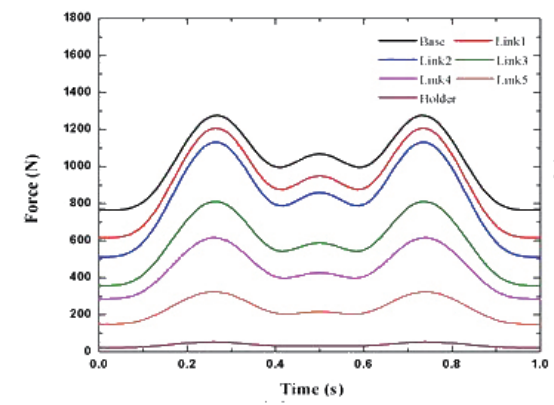

(a)

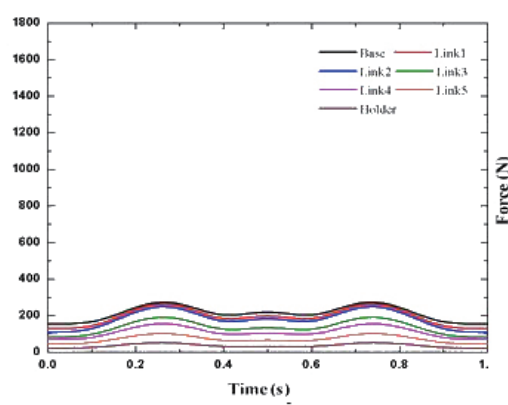

(b)

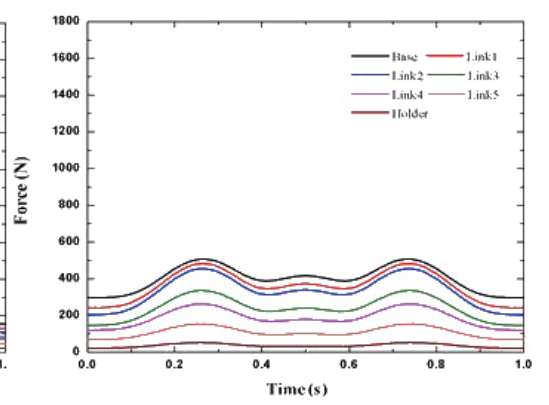

(c)

Fig. 5. (Color online) Force versus time of all robot components: (a) cast iron, (b) polyamide, and (c) aluminum.

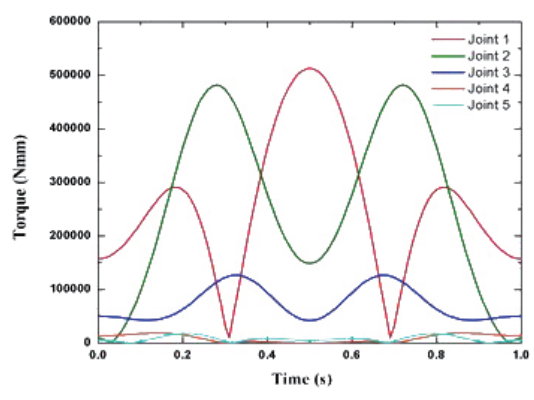

(a)

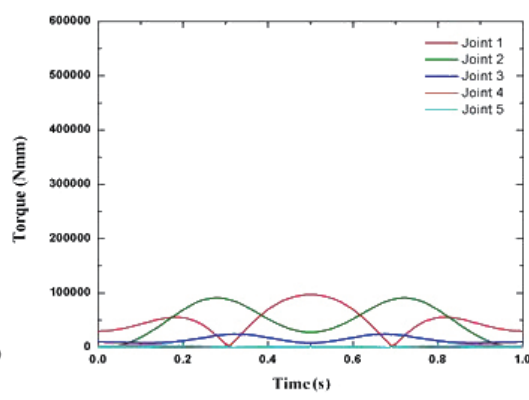

(b)

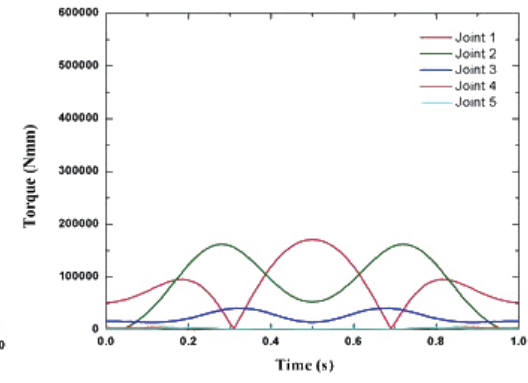

(c)

Fig. 6. (Color online) Torque curves with time simulated for each joint: (a) cast iron, (b) polyamide, and (c) aluminum. 


\subsection{Power consumption}

The power consumption at each joint is further analyzed on the basis of the robot movement from start $\left(\theta=0^{\circ}\right)$ to end $\left(\theta=180^{\circ}\right)$. The payload of the robot must include the weights of the link, holder, and load (window regulator). Figure 7 shows that the power of all joints is relatively low at the start and end of the robot movement path. This is because the motor drive is not loaded owing to low friction. The difference in robot power consumption between polyamide and aluminum is lower than those between polyamide and cast iron and between aluminum and cast iron, approximately 23.26 and $37.21 \%$, respectively.

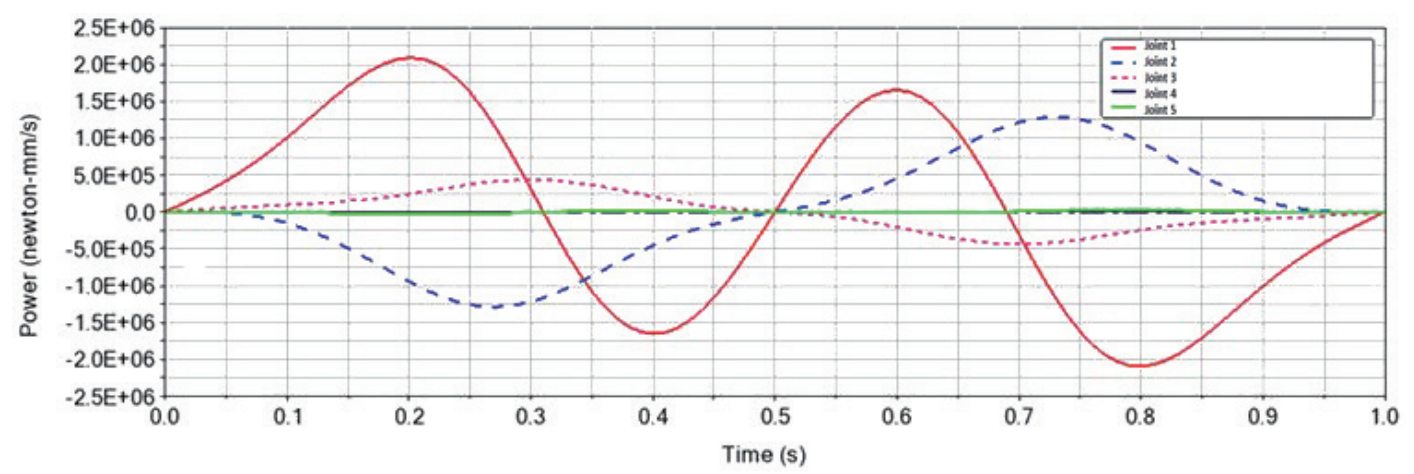

(a)

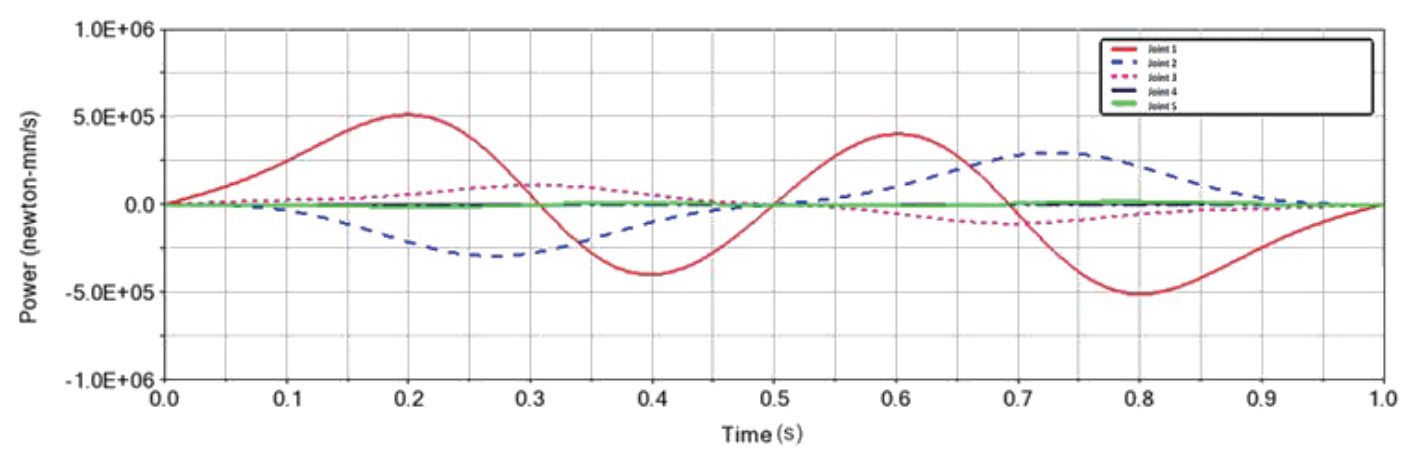

(b)

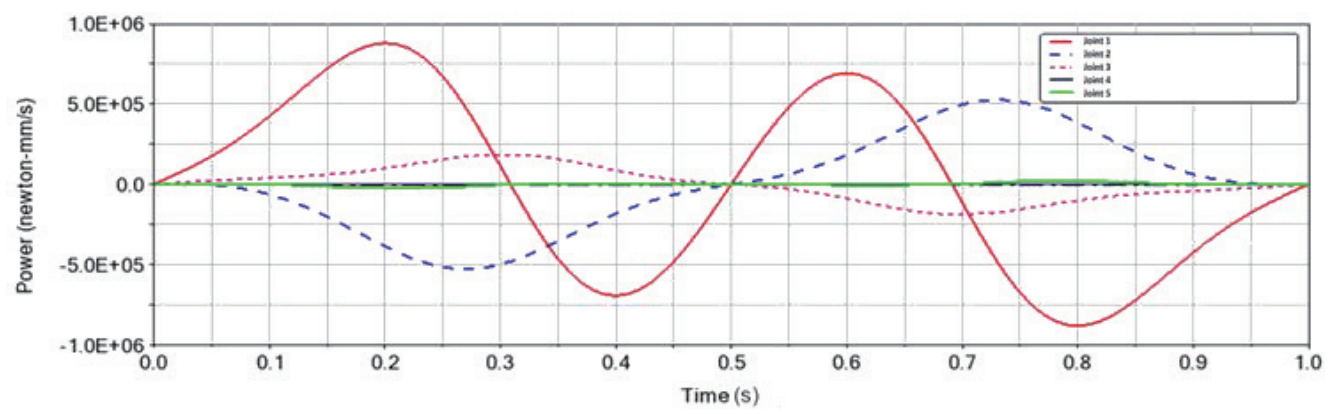

(c)

Fig. 7. (Color online) Power consumption at different joints of the robot: (a) cast iron, (b) polyamide, and (c) aluminum. 


\subsection{Mechanical characteristic}

Static stress is present in the base that is in contact with the ground and connected to link 1 through a rotary joint. It is interesting to investigate this component because the payload and object apply pressure down to the base. In Fig. 8, the static stresses under the total payload (five links + load) are 3.69, 1.42, and $0.759 \mathrm{MPa}$ for cast iron, aluminum, and polyamide structures, respectively. The chance of deformation of the base can be predicted by the yield strength of the material. The smallest amount of deformity is found to be $0.34 \%$ for aluminum, $0.35 \%$ for polyamide, and $1.845 \%$ for cast iron.

The dynamic optimization of the robot arm is significant in improving the operation precision. In the operating system, it is found that the natural frequencies of the robot arm on the base are $65.975,68.335$, and $28.811 \mathrm{~Hz}$ for cast iron, aluminum, and polyamide, respectively. Note that the natural frequency is the frequency at which a system tends to oscillate in the absence of any driving or damping force. Moreover, it induces maximum dynamic stresses of 417,273 , and $33.9 \mathrm{MPa}$, on the base for cast iron, aluminum, and polyamide, respectively, as seen in Fig. 9. Damage is observed on the cast iron structure because the maximum stress exceeds the yield strength of the material.

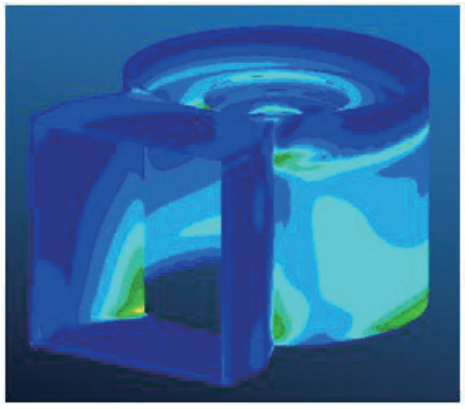

(a)

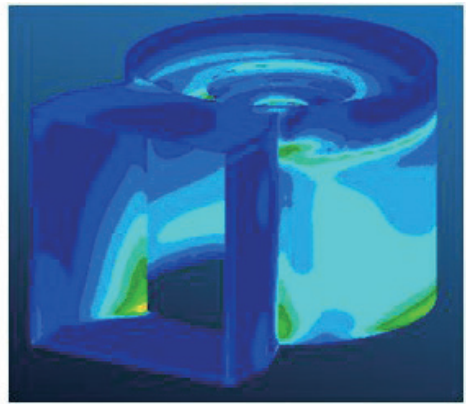

(b)

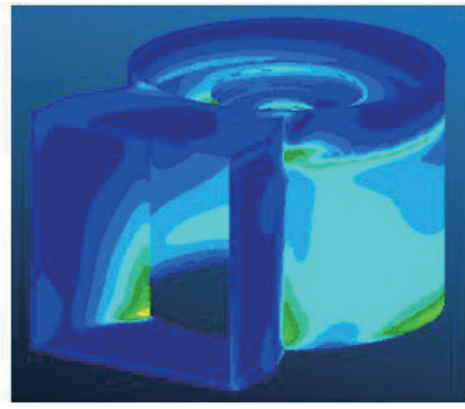

(c)

Fig. 8. (Color online) Static stress of the base of three different robot arm structures: (a) cast iron, (b) aluminum, and (c) polyamide.

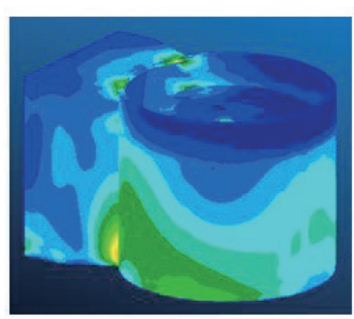

(a)

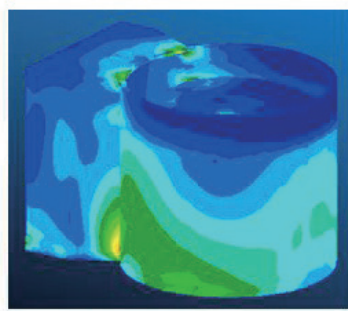

(b)

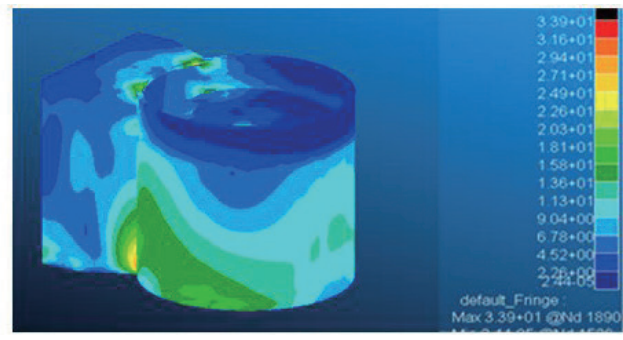

(c)

Fig. 9. (Color online) Dynamics stresses on the bases of three different robot arm structures: (a) cast iron, (b) aluminum, and (c) polyamide. 


\section{Conclusions}

Simulations were performed for a robot arm. Five DOFs, four rotary joints, and one prismatic joint were adopted in the design. Cast iron, polyamide, and aluminum robot components were analyzed using CAE software. The following are our conclusions:

- The applicability of a material was demonstrated in terms of its dynamic and static characteristics; cast iron provided the highest force and torque to drive its components.

- The maximum force was observed along the $x$-axis for the base and the $z$-axis for the links and holder. This is related to the power consumption of each joint.

- The light weight of polyamide was a key factor in reducing the power consumption. The mechanical characteristics of the material were investigated in static and dynamic systems.

- The natural frequencies of the base were $65.975,68.335$, and $28.811 \mathrm{~Hz}$ for cast iron, aluminum, and polyamide, respectively. Damage appeared on the cast iron structure because the maximum stress exceeded the yield strength of the material.

- Polyamide can be used to reduce the weight by $40 \%$ and improve the energy efficiency and cost effectiveness by $41 \%$.

\section{Acknowledgments}

This work was financially supported by NSTDA and TSC (Thai Steel Cable) under grant no. FDA-CO-2560-4351-TH.

\section{References}

1 S. Buthgate, A. Seanthon, and S. Kaitwanidvilai: Int. J. Innovative Comput. Inform. 13 (2017) 659. https://doi. org/10.24507/ijicic.13.02.659

2 B. Siwawong and K. Somyot: Int. Elect. Eng. Congr. (iEECON) 7 (2018) 739.

3 B. Siwawong, S. Anakkapon, and K. Somyot: Int. MultiConference of Engineers and Computer Scientists (IMECS) 2 (2017) 879. ISBN: 978-988-14047-7-0

4 S. Kaitwanidyilai and M. Parnichkun: Eng. Lett. 16 (2008) 1. (SCOPUS)

5 S. Kanprachar and S. Kaitwanidyilai: Proc. Int. MultiConference of Engineers and Computer Scientists (IMECS) 2 (2010) 1471.

6 S. Kaitwanidvilai and I. Ngamroo: Int. J. Innov. Comput. Inform. Control 8 (2012) 91.

7 H. Kumazaki, T. Sugiyama, and H. Oguri: Sens. Mater. 30 (2018) 111. http://dx.doi.org/10.18494/ SAM.2018.1640

8 H. S. Park, X. P. Dang, A. Roderburg, and B. Nau: CIRP J. Manuf. Sci. Technol. 6 (2015) 44. https://doi. org/10.1016/j.cirpj.2012.08.002

9 T. J. Young, L. E. Crocker, W. R. Broughton, S. L. Ogin, and P. A. Smith: Compos. Part A 50 (2013) 39. https:// doi.org/10.1016/j.compositesa.2013.03.014

10 V. A. Buryachenko and M. Brun: Int. J. Solids Struct. 48 (2015) 719. https://doi.org/10.1016/j.ijsolstr.2010.11.009

11 H. B. Ustaoğlu, S. Ayhün, G. Simitçioğlu, S. Süsler, E. Akay, V. Z. Doğan, Z. Mecitoğlu, H. S. Türkmen, and S. Atamer: Int. Conf. Mater. Comp. Perform. Var. Amplitude Loading 3 (2015) 509. https://doi.org/10.1016/ j.proeng.2015.02.061

12 B. Sreenivasulu and G. Prasanthi: Global Cong. Manuf. Manage. 12 (2014) 1187. https://doi.org/10.1016/ j.proeng.2014.12.397

13 Z. Yongqi, T. Qingchang, Z. Kuo, and L. Jiangang: Int. Conf. Appl. Phys. Ind. Eng. 24 (2013) 19. https://doi. org/10.1016/j.phpro.2012.02.004

14 A. Sofi and E. Romeo: Comput Methods Appl. Mech. Eng. 311 (2016) 671. https://doi.org/10.1016/ j.cma.2016.09.009 
15 P. Gélat, N. Saffari, S. Freear, and S. Harput: IEEE Int. Ultrasoni. Symp. Proc. (2015) 104. https://doi. org/10.1109/ULTSYM.2015.0319

16 Z Liu, L.-B. Song, Y. Li, and B.-Z. Pan: IEEE Int. Conf. Mech. System Control Eng. (2017) 96. https://doi. org/10.1109/ICMSC.2017.7959450

17 N. Anzai, M. Fujita, K. Sakamaki, and Y. Kariya: iMPACT International Microsystems, Packaging, Assembly and Circuits Technology Conf. (2017) 120-123. https://doi.org/10.1109/ IMPACT. 2013.6706623

18 D.-T. He and Y. Guo: Int. Conf. Ubiquitous Robots and Ambient Intelligence (URAl) 13 (2016) 772. https:// doi.org/10.1109/URAI.2016.7733979

19 Y. G. Soloveichik, M. G. Persova, and D. V. Vagin: Int Sci. Tech. Conf. APETE 13 (2016) 339. https://doi. org/10.1109/APEIE.2016.7806948

20 Y. Wang, L. H. Zhong, X. H. Yu, Y. B. Wang, and C. Y. Xie: Int. Conf. Modelling, Identification and Control (ICMIC) 9 (2017) 290. https://doi.org/10.1109/ICMIC.2017.8321656

21 Z. Zhakypov and J. E Paik: IEEE Trans. Rob. 34 (2018) 151. https://doi.org/10.1109/TRO.2017.2775655

22 S.-y. Yoo, B.-H. Jun, H. Shim, P.-M. Lee, and B. Kim: MTS/IEEE OCEANS-Bergen (2013) 104. https://doi. org/10.1109/OCEANS-Bergen.2013.6608156

23 L. Liu and Y. Yao: Int. Conf. Electron. Packag. Tech. (ICEPT) 18 (2017) 197. https://doi.org/10.1109/ ICEPT.2017.8046437

24 K.-S. Lee, S.-J. Park, and T.-K. Han: IEEE Int. Forum Strategic Technology (2017) 77. https://doi.org/10.1109/ IFOST.2007.4798526

25 Y Wang, J. Yang, and S. Wang: Int. J. Innovative Comput. Inform. Control 14 (2018) 561. ISSN 1349-4198

26 M. Begnini and D. W. Bertol: Int. J. Innovative Comput. Inform. Control 13 (2017) 341. https://doi.org/10.3233/ JIFS-17699 